\title{
Initiating the development of an integrated waste management curriculum
}

\author{
W.D. Conn \\ Virginia Polytechnic Institute and State University, Blacksburg, VA, USA
}

\begin{abstract}
\end{abstract}
The National Recycling Coalition, in recognition of significant changes in the field of solid waste management and the resulting need for people with new knowledge and skills, has assembled a committee to develop an "integrated waste management curriculum." This paper identifies and discusses several possible objectives for such a curriculum, and explores issues associated with different ways in which it might be initiated.

\section{INTRODUCTION}

Early in 1991, the National Recycling Coalition (NRC) assembled a small group of solid waste management "experts" in a committee to develop an "integrated waste management curriculum." The primary impetus, it seems, came from a recognition of the dramatic changes that have taken place in the field of solid waste management during the past few years, the move toward an integrated approach, and especially the recent growth in the number of local and regional recycling programs initiated throughout the United States. These developments result in the need for people with appropriate knowledge and skills, not only to design and run the programs themselves, but also to provide the political support necessary for their implementation and to be effective participants at a personal level (for example, in seeking ways to reduce waste, in segregating appropriate materials for recycling, and so on ).

At the committee's first meeting (by conference call), some basic issues were raised regarding the precise purpose of a curriculum in integrated waste management (IWM), as a prelude to discussing the nature of such a curricu-

Correspondence to: W. David Conn, Virginia Polytechnic Institute \& State University, Blacksburg, VA 24061-0113, USA. 
lum and how it might be developed and implemented. Although the committee subsequently made progress in defining tasks to meet the NRC's immediate needs, most of the basic issues remain unresolved. This report briefly summarizes these issues and offers some of the author's thoughts about them.

\section{Objectives and types of possible curricula}

The committee recognized that it is impossible to sensibly discuss the nature of an IWM curriculum without first establishing its objectives. A number of possible objectives can be identified, including the following:

- To contribute to the development of "environmental literacy" among students generally.

- To educate specialists in IWM.

- To provide a training in IWM skills.

- To provide non-specialists with a limited exposure to IWM.

Environmental literacy

An IWM curriculum might be used as part of a general effort to improve the environmental literacy of some or all students, especially at the undergraduate level. Regardless of their students' particular career goals, many colleges and universities (not just those with an explicit Liberal Arts focus) offer a "core" program of liberal study, intended to enrich the education of everyone. Often the core includes an exposure to societal issues that are pressing now and/or are thought likely to be pressing in the future. Environmental issues certainly fall into this category.

Furthermore, many people acknowledge the need for those in the highly industrialized nations to move away from the "use and discard" mentality that has been so prevalent in the past (and largely remains so today). Since just about everybody, in one way or another, both generates and disposes of waste, it is arguable that all would benefit from some exposure to the "new thinking" in waste management that IWM represents, focusing especially on waste reduction and recycling. The core curriculum provides an opportunity for this to happen, at least for college students.

Educating IWM specialists

Another possible objective for an IWM curriculum would be to educate specialists in waste management. The word "educate" is used here advisedly, for the intent would be to do more than just imparting "how-to" technical skills. To be successful, waste managers increasingly must draw on the knowledge bases of many different disciplines and fields, including the natural, biological, and social sciences as well as engineering, business, and law. While mastery of all of this knowledge is obviously infeasible (and unnecessary), a student should learn how to gain access to it and should develop the analyti$\mathrm{cal} /$ synthetic skills required to make use of it in an applied context.

Although the committee gave some thought to the possibility of an undergraduate "major" devoted to IWM, the topic may be too narrow to warran such single-minded attention. More appropriate at the undergraduate level, perhaps, would be for IWM to be offered as an area of concentration or "minor" in a broader field such as environmental studies, sciences, or engineering. At the graduate level, a narrower focus on IWM may be more appropriate, especially in a professional master's program, although once again in many cases the most sensible approach may be to incorporate an IWM curriculum into a broader field. Of course, there is no one "correct" way of proceeding; some diversity of offerings by different universities and colleges is both healthy and desirable.

Training in IWM skills

Skills training is appropriate for at least three groups of people: those who lack the ability or the desire or for some other reason are unable to seek opportunities in higher education, but who wish to become qualified as technicians; those whose college degree programs, through design or otherwise, failed to provide these particular skills; and those wishing to update or expand upon skills previously obtained.

A wide variety of options are possible, ranging from short (1-2 day) workshops and seminars to individual full-length courses to multi-course sequences. They may be taken without academic credit or with some kind of credit (often in Continuing Education Units) toward a diploma or certificate. Another possible option is a program leading to an associate degree.

There is also a diverse set of institutions, both public and private, that might offer some or all of these options, including the continuing education/extension divisions of four-year colleges and universities, two-year community colleges, and professional/trade schools, as well as various professional associations and institutes. Correspondence and distance-learning (satellite) courses are also a possibility (such as the solid waste course offered by the University of Wisconsin through the magazine Waste Age).

Exposing non-specialists to IWM

There are many people who may desire or need to know something about IWM - for example, the basic principles and concepts involved - withou necessarily becoming specialists. Such people are likely to include elected and appointed government officials (at all levels), corporate managers, concerned citizens, and others who are involved in decision-making about waste management or whose support is important for a successful program. Although in the past decisions about waste management have often been left to the "technical" staff (typically those trained in engineering and/or public 
health ), nowadays they almost always attract considerable attention in the political arena. This is not inappropriate, since these decisions frequently involve difficult social and economic trade-offs (which hinge on values and are not simply technical in nature); however, it is important that those participating in the debate have access to the best available technical information about the waste management options and their associated impacts.

To some extent the needs of these people might be served by training seminars and courses of the kind already mentioned, but often these will focus (by design) too much on "how-to" information; instead, special offerings might be developed for this audience, in the form of short presentations, workshops, and seminars. Again, a broad range of institutions, as well as individuals with appropriate expertise, could make these offerings which migh be given, for example, at professional meetings (e.g., those attended by city managers, planning commissioners, etc.) or at citizens' conferences.

\section{Issues associated with initiating an IWM curriculum}

In the absence (to the knowledge of this author) of any systematic survey of existing IWM-related offerings, it is impossible to say how much of what has been discussed is already available. Certainly, based on formally-documented as well as informal anecdotal evidence, there currently exist or are being planned a number of opportunities for education and training in IWM. The idea of introducing "environmental literacy" into the undergraduate core is receiving quite widespread attention, and IWM may be included in courses developed for this purpose. Some institutions may choose to follow the lead of Tufts University which has been encouraging (and helping) its faculty to find ways of introducing environmental considerations into all coursework regardless of discipline or subject-matter; such an approach may lend itself well to discussing IWM, since there are so many different aspects to waste and waste management. A language course, for example, might include a discussion (in French) of recycling in France, while a course in anthropology might explore the cultural basis of attitudes toward waste.

Many college and university programs in environmental studies, sciences, and engineering, as well as some in business, planning, and law, already offer electives, at least, that relate to IWM. A problem is that, in general, college and university curricula are notoriously slow to change; furthermore, when they do change, they tend to do so incrementally rather than in dramatic fashion. This is especially true of programs subject to professional accreditation, where significant curricular alterations may be subject to external as well as internal approval.

Consequently, due to the relatively recent incorporation of IWM into official national and state policy (for the first time making it the "fashionable" approach to waste management), it is to be expected that the associated (and critical ) change in mindset - giving first priority to pollution prevention rather than "end-of-pipe" control - is not yet fully reflected in existing educational programs. Furthermore, since the key to successful pollution prevention is often as much behavioral as it is technological, some traditional fields such as engineering may be having difficulty in making the adjustment. In most colleges and universities, interdisciplinary courses and programs (essential to the comprehensive coverage of IWM) are more difficult to establish than those that remain within traditional disciplinary boundaries.

Despite these barriers, there are (as previously mentioned) several examples of successful efforts to incorporate IWM into existing or new curricula, some pre-dating the shift in government policy that has come to favor this new approach to waste management. Solid waste engineering classes, while still tending to spend most time on landfill and combustion, are starting to pay more attention, it seems, to waste reduction and, especially, to recycling Programs in environmental science, environmental engineering, and natural resources at Rutgers, Wisconsin-Madison, and Michigan (respectively) are profiled in a 1989 article in BioCycle that focuses on educating students for careers in recycling, while other programs at SUNY-Stony Brook, Michigan State, Cincinnati, Tufts, Clemson, and North Carolina-Chapel Hill are also mentioned [1]. At Virginia Polytechnic Institute \& State University (and previously, during the 1970 s, at UCLA), the author has taught solid waste management as well as more general pollution control planning/policy courses in which considerable emphasis has always been given to waste reduction and recycling.

To the author's knowledge, relatively few full-fledged training programs in IWM are currently in place, exceptions including the Certificate Program in Waste Management at SUNY-Stony Brook [2] and other options offered (through continuing education) by such universities as San Francisco State, UCLA, and Wisconsin-Madison. Undoubtedly, others are being developed by both public and private institutions, since the potential market for such programs is growing rapidly as a result of the pressure placed on waste management authorities to practice IWM. New state mandates across the U.S. for example, have caused the creation of a huge number of positions as recycling coordinators (more than 50 in California alone), in many cases almos overnight. One of the problems facing institutions that attempt to respond to this demand is in finding suitably qualified instructors, since there are not yet many people around who have the necessary knowledge, experience, and teaching ability.

Judging from the meeting agenda of numerous professional organizations and citizen groups, the greatest progress to date in teaching about IWM may have been made in making presentations designed to alert non-specialists to its nature and purpose, as well as to its status in federal and state legislation. Arguably, an advantage of these presentations is that they may help to build 
and maintain pressure on waste managers and others to adopt an IWM approach, as well as developing political support for the allocation of necessary resources and other decisions affecting implementation. There is a danger, however, that IWM may be viewed by some as just another "fad," receiving a temporary flurry of attention on the conference circuit. It is important, therefore, for people to come to understand the significance of the fundamental shift in approach to waste management that IWM represents.

\section{CONCLUSION}

Although the NRC initially asked the committee to develop an IWM curriculum, it is evident that several different curricula might be developed to serve several different purposes. Realistically, with regard to possible offerings in degree programs by four-year colleges and universities (with which the author is most familiar), it is unlikely that the development of one or more curricula by an outside group - such as NRC's committee - would have much direct influence, at least in the short term. For the most part (although not always), faculty members in particular institutions jealously protect their sole right to make decisions on matters of curriculum. They typically try to resist the attempts of accrediting agencies, for example, to infringe upon this right, although in practice some compromise is occasionally reached in order to achieve accreditation. Under these circumstances, perhaps the role of the NRC should be to plant ideas in faculty minds, maybe going as far as to suggest possible ways of incorporating IWM into various curricula. The Coalition might try to influence accrediting agencies, but by doing this directly it would run the risk of alienating the by-passed faculty.

In the short term, the NRC might have more success in influencing the adoption of curricula for IWM training offered, for example, through continuing education programs. It is already quite common for training courses of this kind to be designed to meet the specifications of outside organizations, which may also provide the instructors and award some kind of diploma or certificate on successful completion. An added advantage, particularly for the training of technicians, is that the certification of such courses (which might otherwise be quite idiosyncratic in content and rigor) could potentially be made uniform throughout a state, a region, or even nationally. This could be of considerable benefit to public works directors and other prospective employers.

\section{ACKNOWLEDGEMENT}

This paper owes much to the initial deliberations of NRC's Integrated Waste Management Committee. Apart from the author himself, the membership includes Rick Anthony (convenor), Melvin Finstein, Sheldon Reaven, and
Kenneth Stern. Any opinions expressed are those of the author alone and do not reflect an official view of the NRC, the Committee, or Virginia Polytechnic Institute \& State University

\section{REFERENCES}

1 Riggle, D., 1989. Training students for a recycling career. Biocycle, October: 33-34, 70. 2 Reaven, S., 1988. One person's opinion: we need a model professional recycling curriculum. Resour. Recycl., September/October: 36-37, 66. 